\title{
RECENT PROGRESS IN THE MANUFACTURE OF GLASSES FOR PROTECTING THE EYE FROM INJURIOUS RADIATIONS.*
}

BY

\author{
W. W. COBLENTZ, Ph.D.
}

Associate Physicist, Bureau of Standards.

THE old saying that it is an ill wind that blows no one good, is well illustrated in the manufacture of optical glass.

One of the chief requirements in the manufacture of optical instruments is a colorless glass. Iron is the most common substance which causes discoloration in, and hence diminishes, the transmission of optical glass. On the other hand, iron impurities in glass have a marked absorption in the infra-red, the maximum being at about $\mathrm{x} \mu$. This property may, therefore, be utilized in the manufacture of glasses for protecting the eye from infra-red rays.

Although it has not been definitely proven that infra-red rays are injurious to the eye, there seems to be a feeling that protection from these rays should be provided. Fortunately this can be done easily and cheaply. And now the most pampered can be provided with glasses which not only give protection from rays which are known to be injurious, but also supply the most exacting demands as to color, etc.

It is of interest to consider the transmissive properties of various glasses which, used separately or in combination, protect the eye from injurious radiations-particularly from ultra-violet rays.

The ideal glass would be one which absorbs all the ultraviolet and infra-red, and transmits only the visible rays, by an amount sufficient to prevent irritation and injury to the eye.

Four years ago the question of providing glasses for protecting the eye from injurious radiations was practically new and untouched. At that time the feeling was expressed ${ }^{1}$ that: "It appears as though in the near future glasses fulfilling every

* Communicated by the Author.

1 Jour. Franklin Institute, May, igi3. 
requirement will be obtainable, and it speaks well for American enterprise to be willing to spend a few dollars in attempting to produce devices for safeguarding the health and contentment of the public."

In the meantime, this prediction has become a reality. The subject of eye protection has become national in importance, and manufacturers of eye protective glasses are meeting the most stringent requirements.

FiG. I.

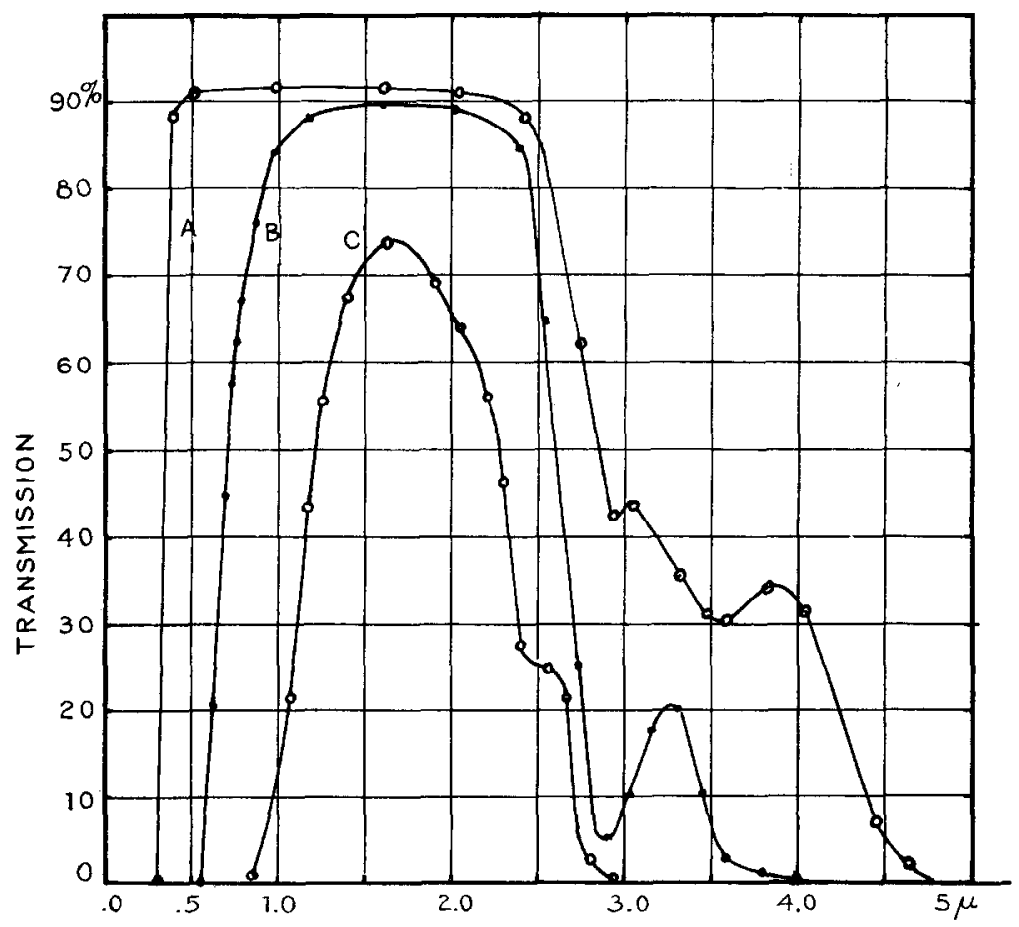

The variety of ways in which various manufacturers of eyeprotective glasses fulfill these requirements, will be noticed in connection with the transmissive properties of various glasses, which will now be discussed. In most cases these glasses were about $2 \mathrm{~mm}$. in thickness. More detailed data may be obtained by consulting the original paper.'

Colorless Glass.- It is of interest to note the characteristics

${ }^{2}$ Bull. Bur. Standards. I4, p. 66.3, тог 8. 
of optically colorless glass. Curve $A$, Fig. I, gives the transmission of a sample of white crown glass which transmits ultraviolet to about $0.3^{\mu}$ and infra-red to about $4.8 \mu$. The shallow absorption bands at $2.9^{\mu}$ and $3.6 \mu$ are characteristic of glasses.

The presence of iron impurities produces a marked change in the transmission of a glass with an absorption band at about I.I $\mu$. This is illustrated in curves $A$ and $C$ of Fig. 2, which

FIG, 2.

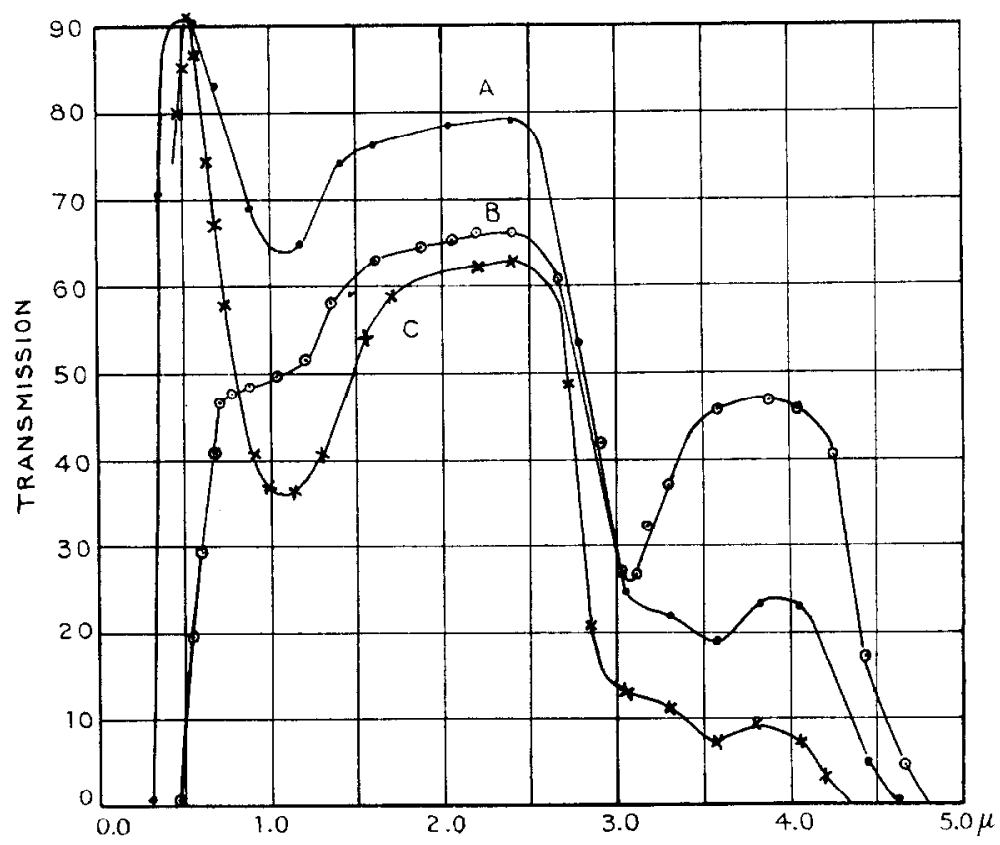

gives the transmission of window glass. Viewed edgewise, such glass appears tinged green.

Red Glass.-Curve $B$, Fig. I, shows that red glass absorbs the ultra-violet and most of the visible rays. But it affords practically no more protection from infra-red rays than does clear glass.

Amber Glass.-As illustrated in Curve B, Fig. 2, amber glass absorbs the ultra-violet and some of the visible spectrum. Iron impurities produce an absorption band at I.I $\mu$. Aqueous solutions of iron alum have an absorption band at about $\mathrm{I} \mu$.

Green Glass.-Curves $A, B$ and $C$. Fig. 3, show that green 
glass is opaque to the ultra-violet and has a wide absorption. band in the region of $\mathrm{I} \mu$. In combination with other glasses, it affords suitable protection from injurious rays.

Blue Glass.-Curve A, Fig. 4, gives the transmission of a sample of cobalt blue glass. In spite of the fact that blue glasses transmit ultra-violet, they are used in some high temperature work. Combined with a deep amber, red or green glass, it affords protection from injurious rays. For example, Curve $C$, Fig. 5, gives

FIG. 3.

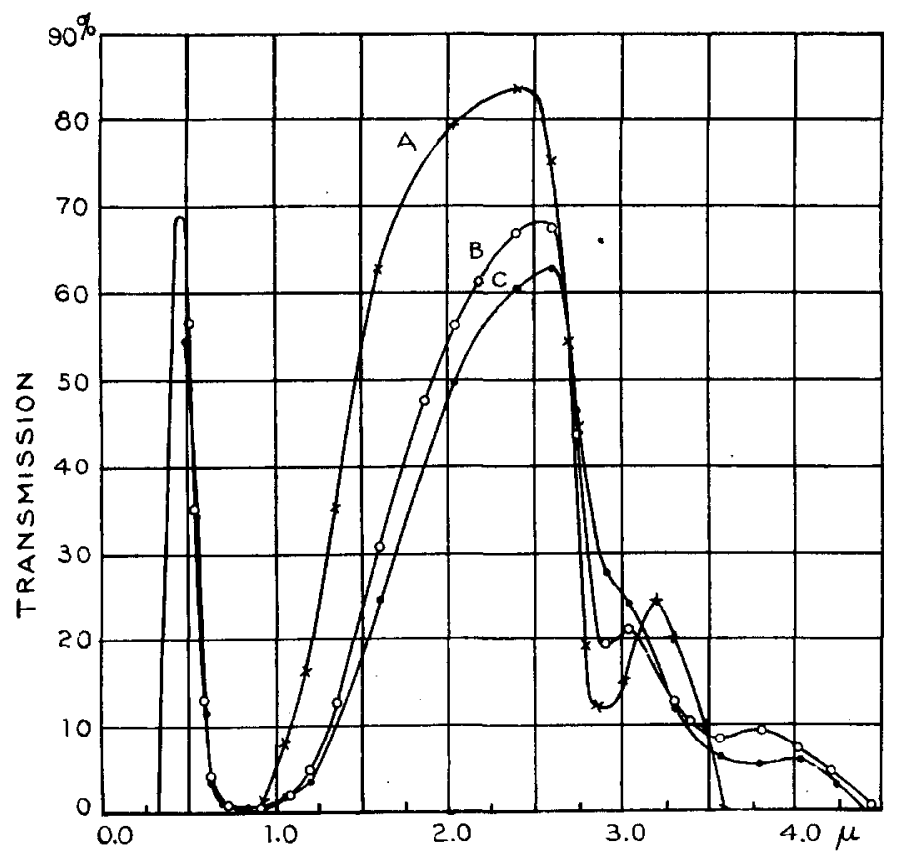

the transmission of a combination of several red and blue glasses used in arc welding. Curve $D$, Fig. 5, gives the transmission of a combination of a flashed red, a green and a blue glass used in oxy-acetylene welding. These two combinations were found to reduce the intensity of the visible rays by a suitable amount, and they afford proper protection from the infra-red and especially the ultra-violet. (In these two curves, $C, D$, Fig. 5, the transmissions are double the values indicated on the scale.)

Sage Green and Blue Green.-Two excellent glasses for 
FiG. 4.

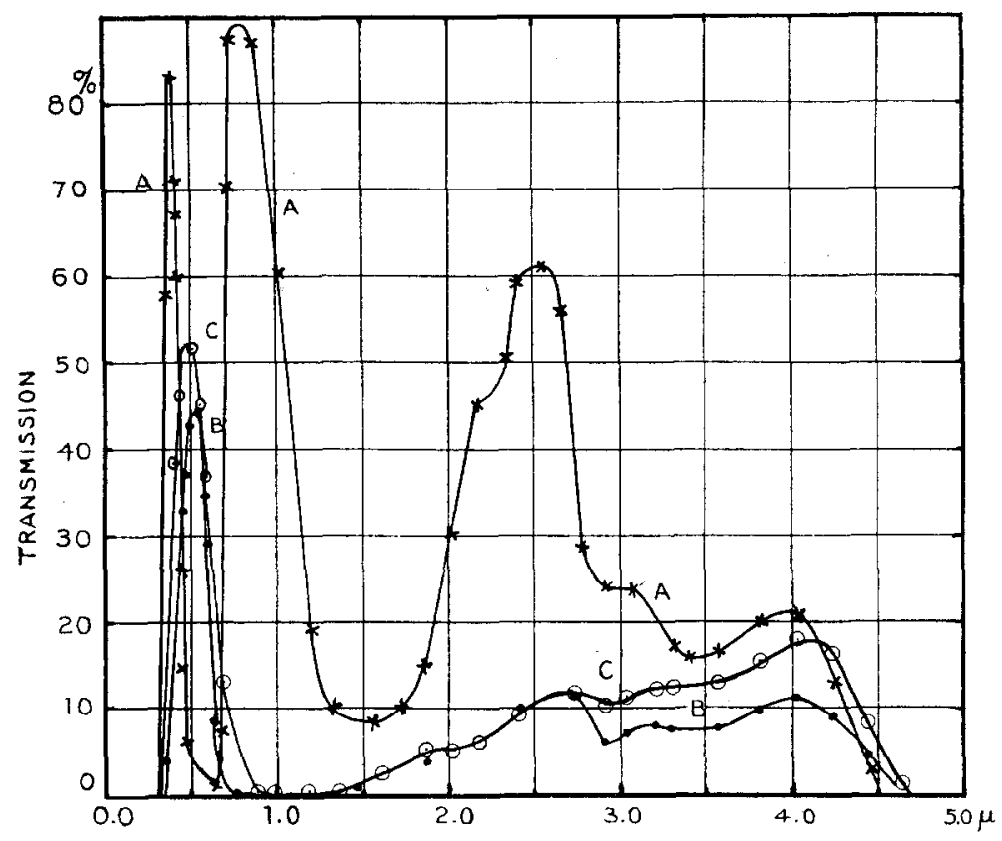

FIG. 5.

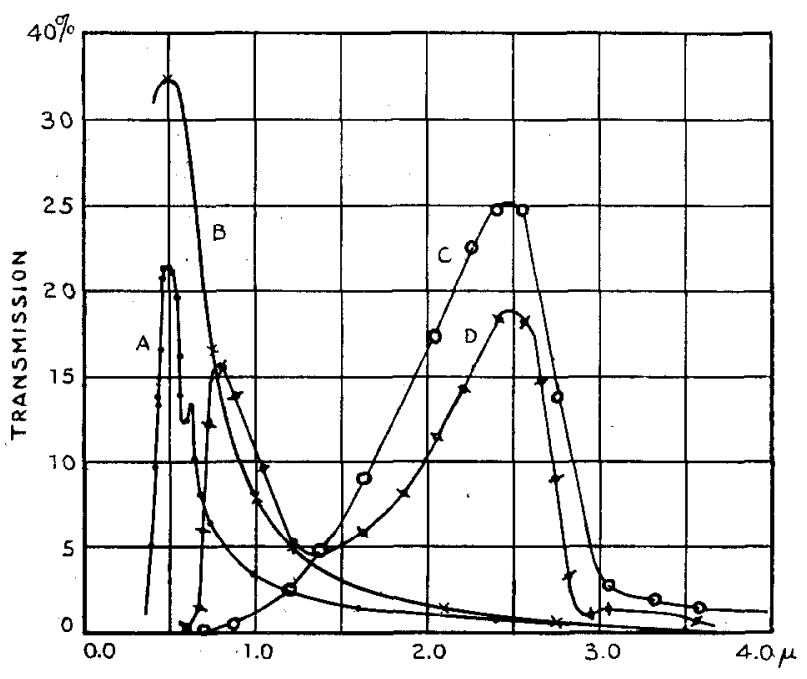


absorbing the ultra-violet and infra-red are Crookes' ferrous sage green (American Optical Co., Curve B, Fig. 4), and Corning $C$, I24 J.A., Curve C, Fig. 4.

Gold Leaf.-A thin film of gold on glass (obtained from $A . O . C$, ; see Curves $A$ and $B$, Fig. 5) eliminates the infra-red and ultra-violet, and by selecting the proper density provides also protection from visual rays.

Black Glass.-Ordinary "smoke" glasses are good for outdoor wear, but they do not give sufficient protection when working near sources of intense ultra-violet radiation.

FIG. 6.

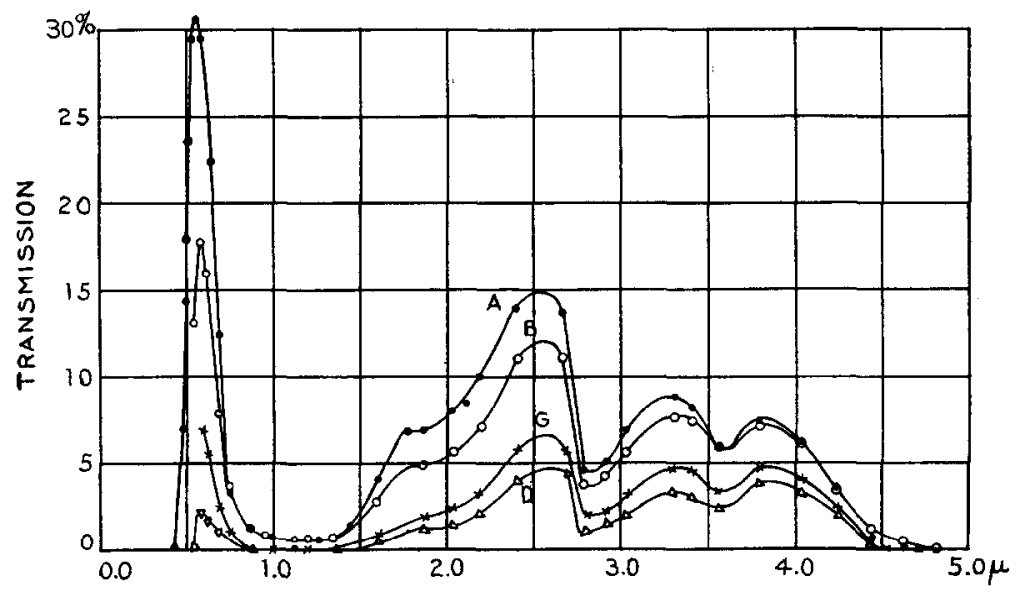

Judging from the small number of "black" glasses submitted for test, in comparison with other glasses used in oxyacetylene welding and cutting, it would appear that the so-called deep "black" glasses are not used extensively.

Novizueld.-This is a commercial eye-protective glass (Corning Gl. Works) which effectively absorbs the ultra-violet and infra-red rays. The transmissive properties of various shades are shown in Fig. 6.

Dyes.-Attempts have been made to use dyed celluloid films instead of colored glass for protection against harmful radiations. In this manner it seems feasible to absorb the ultraviolet and visible rays. But the writer knows of no dye which has marked absorption throughout the infra-red. As shown in Curve $C$, Fig. I, a sheet of celluloid which is dyed so as to be 
opaque to the visible and ultra-violet, is quite transparent in the infra-red.

The published data of others ${ }^{3}$ shows that dyes (e.g., green and violet dyes) which absorb the yellow and red become quite transparent in the infra-red. Hence, unless a dye is found which absorbs the infra-red, the outlook for substituting dyed films for colored glasses, for absorbing the infra-red, is not very encouraging.

The foregoing is a brief description of the characteristics of glasses readily obtainable, which singly or in combination afford protection from injurious radiations.

Washington. D. C., April r5, roig.

'Pfund. Zeitschr. Wiss. Photog., 12, p. 34I, I913; Johnson and Spence, Phys. Rev. (2). 5, p. 349, r9r5.

Precious Stones in the United States. (U. S. Geological Survey, Press Bulletin, July, I919.) - The value of the precious stones annually produced in the United States from the beginning of this century to 19I4 has been about one-third of a million dollars. In I9I4 and in every year since, the annual value of the output has dropped considerably, and in 1918 it dropped to $\$ 106,523$, the lowest reported since the United States Geological Survey began to collect statistics of gem production, in I883, with the single exception of 1896 , when it was $\$ 97,850$.

The report on the production of precious stones in I9I8, just published by the Survey, ascribes the decrease in the value of the precious stones produced to the military enlistment of many gem miners, the general scarcity of labor, and the poor market.

The output consisted chiefly of the sapphire variety of corundum, which is nearly all used as mechanical bearings in watches and other instruments that require practically nonwearing frictionless bearings. Other less valuable and softer minerals used for this purpose are garnet and some forms of hard, compact silica, known as agate and chalcedony. The annual value of the output of the four gem minerals, corundum, quartz, tourmaline, and turquoise, amounts to over four-fifths of the total value of all the precious stones produced in the United States.

Montana, Nevada, California, Colorado, Maine, and Arizona are the chief gem-producing States, but from 20 to 30 States annually report some production.

Several relatively large diamonds were found in Arkansas in I9I8, notably a canary-colored octahedron weighing nearly i 8 carats and a number of smaller stones weighing several carats each.

VoL. 188, No. I124-19 